\title{
A Research on Improving the Competiveness of Grain and Cooking Oil Processing Enterprises
}

\author{
Haijuan Tian \\ Jilin Business and Technology College, Changchun Jilin, 130015, China
}

Keywords: Grain and Cooking Oil Processing Enterprises, Enterprise Competitiveness, Methods.

\begin{abstract}
The increasing development of economy and technology promote the growth of grain and cooking oil processing enterprises. At the same time, the increasing development of grain and oil enterprises also makes the market competition fierce. If the grain and cooking oil processing enterprises want to survive in the cruel competitive market, they must adopt effective measures to improve self competitiveness. Therefore, how to promote self competitiveness has become a key problem for all enterprises to deal with. This paper makes a deep analysis of the competitiveness of grain and cooking oil processing enterprises and presents valid methods for enterprises' reference.
\end{abstract}

\section{Introduction}

China is a big agricultural country and the annual output of agricultural products is very considerable. With the entrance into WTO, the grain and cooking oil market has been impacted by the foreign companies. In this situation, if our grain and cooking oil enterprises want to better survive, we must take effective methods to improve our competitiveness. Only in this way can we get a foothold in the market and develop ourselves stably.

\section{The Connotation about the Core Competence of the Grain and Cooking Oil Processing Enterprises}

The concept of the core competence of enterprises is proposed in 1990 by Hamel and Prahalad, two famous professors. In their views, core competence means the unique techniques that can obtain economic benefits for the enterprise. Meantime, they also put forward the "tree mode theory" in which the enterprise is compared to a tree with a trunk, branches, flowers, fruits and other parts which can find their counterparts in the enterprise's department. For example, the core products are trunk and all departments are branches, flowers. When the tree wants to grow, the most important part is the root. Only when the root absorbs the nutrition continuously, can the tree keep growing. Therefore, the most important part of the enterprise is core competence. The enterprise can have advantages and stable development as long as it gets core competence[1]. In view of the above, the two professors make a deep conclusion on the connotation of the core competence: "the core competence of the enterprise is accumulated during the development of the enterprise and mostly contains in the enterprise culture which express in the inner characteristics of the enterprise. It is the technique which is different from that of the other enterprises and can not be imitated. It can provide motivation in the development of the enterprise and make a foundation for the long-term development of the enterprise in the fierce market competition." Besides, the core competence of the enterprise involves a wide areas, so if we want to promote the core competence,we should do it in many sides. Only do it like this, can we improve the core competence effectively and bring advantages during the development of the market.

\section{The Effective Measures to Promote the Competitiveness of the Grain and Cooking Oil Processing Enterprise}

\section{Conduct Innovation.}

Innovation is the motivation and the source of the eternal development of the enterprise. If an enterprise always adhere to the old habits, it will be eliminated in the developing trend of the society. 
Therefore, if the the enterprise wants to improve self competitiveness, they must conduct innovation which can be developed from the below sides:

Firstly, conduct technique innovation. Compared with the foreign grain and cooking oil processing enterprises,our native enterprises are at a disadvantage in the technical side which make the native enterprises less competitive in the market competition.for a long time Continuous development, the enterprise obtains less economic benefits than before, and some small enterprises even face bankruptcy. Gradually, China's grain and cooking oil processing market will be soon occupied by foreign enterprises, so as to influence the economic development of our country. The main reason to cause this situation is because of the backward in technique of China's grain and cooking oil processing enterprises.Besides, our Independent innovation ability is relatively weak, the use of technology and machinery are mostly imported from abroad[2]. It is acknowledged that the technique enterprises spend a high price to import will not be the core technology of foreign enterprises what will make our technology level far behind foreign enterprises. When the enterprise fail in the beginning line, if we want to catch up with the enterprise front, it must to conduct self innovation. Thus, the work of scientific research personnel should be strongly supported by the Enterprises by providing what they need to study the advanced technology and form a parent technique.in this way, the technique that enterprise apply will become unique. The technique advantage will provide a good foundation for the enterprise to develop better.

Secondly, create management innovation. In the actual operation, enterprises need to carry out all management work. If the management is not in place, it will cause problems in the operation, which will lead to problems in the enterprise itself. When it happens, the enterprises will be difficult to keep developing. Therefore, it is necessary to innovate the management mode and improve the management level. Enterprise management ranges widely and we need to conduct innovations in a various fields, for example, the management system, management methods, management culture, and so on. At present, the management of China's grain and cooking oil processing enterprises is relatively backward, and some enterprises still use the traditional management methods to carry out management work so that the enterprise management means cannot meet the needs of the current situation and management is not in place. In this case, enterprises should change their management concepts, and establish a sound management system with innovative management methods and advanced management tools, and then implement the management work effectively to the actual work, and fully play the role of management [3]. At the same time, enterprises can analyze the advanced management experience of foreign countries and combine their own characteristics to build a sound management system, realizing the transform from the production management to the capital management.

Thirdly, system innovation. In the process of enterprise development, the rules and regulations are essential. If an enterprise's system is not perfect and advanced, then there will be serious problems when enterprise conducts the management work according to the system, or carry out technological innovation. Therefore, it is imperative to innovate the system. Enterprises should set up the modern enterprise system according to their own situation and experiences from some advanced rules and regulation, in this way we can provide an important basis for enterprises to carry out technological innovation and management innovation. Everything will be done under rules and regulations, and then twice as much can be accomplished with half the effort. At the same time, enterprises should restructure and joint to reform their existing stock system and realize the effective conversion of enterprise management mechanism. In addition, enterprises should clear all the rights and obligations to ensure that the property rights of enterprises are distinct. On the basis of that, we can conduct scientific and reasonable management to ensure long-term development of enterprises.

\section{Make a Development Strategy Scientifically.}

As long as an enterprise wants a long-term development, they must make a distinct development strategy. If the enterprise makes an unrealistic plan, it will bring problems in the process of development, it will cause economic decline in the slight side and even will bring to bankrupt to a serious level. Therefore, enterprises must pay high attention to the development strategy, using 
scientific methods to it. Laying down an enterprise development strategy scientifically should follow the below steps:

Firstly, determine the development thoughts. There are two kinds of development thoughts for enterprises. One is single and simple and the other is pluralistic. These two kinds of thoughts are of advantages itself. in the process of determine the development thoughts, the enterprises should combine themselves with the current situations.only when we determine the development thoughts can we improve ourselves effectively. According to the facts of China's grain and cooking oil processing enterprises, the pluralistic mode fits for the large enterprises. Generally, the large enterprises are of advantages and strength in the market. Accordingly, these enterprises can enrich themselves and improve market competitiveness by many-sided development. On the other side, for some medium and small enterprises, their capital is limited and technology is not advanced. If these kind of enterprises develop in pluralistic ways, they will not be proficient in any aspects and not in the possession of any outstanding advantages. In this case, they can barely survive in the market.in conclusion,this kind of enterprise should apply single development strategy and put all eggs into one basket.In that way, the enterprises will be advanced in some fields and form core competence which will bring out advantages in the market[4].

Secondly, implement brand strategy. Enterprises should implement brand strategy to create their own brands step by step in the process of actual development. When an enterprise's brand is known by the public, the economic benefits it brings will be upgraded. In recent years, our country's grain and cooking oil processing industry has produced a group of brands, such as Luhua edible oil and Beidahuang rice. Common people are familiar with these brands and they tend to choose them when purchasing products, which makes these products' sales volume larger than that of some unknown products. Therefore, in order to gain market share, grain and cooking oil processing enterprises should formulate brand strategy, create their own brands in the process of development, improve product quality accordingly, try to obtain customer acceptance, and thus to gain more economic benefits.

\section{Integrate And Optimize, Enlarge And Strengthen.}

There are many grain and cooking oil enterprises in our country, among which some large-scale ones have a stronger daily production capacity while some small ones have a weaker daily production capacity. However, the number of these small enterprises is relatively bigger, which makes our country's grain and cooking oil processing enterprises small, feeble and sporadic. In other words, our country lacks enterprises that are large-scale, strong and preponderant, which makes our domestic enterprises temporarily outgunned when compared to foreign ones. Small enterprises have problems of talent shortage, scanty of fund and backwardness of technology in the process of development. And these problems make small enterprises hard to expand and unable to shape scale benefits. Some large-scale enterprises have strong funding, abundant resources and advanced technology. They should make full use of these advantages, use funds appropriately, make better management and carry out technology innovation by restructuring so as to optimize organizational and capital structure and to further enhance their competitive power, making them preponderant enterprises.

\section{Implement Talent's Strategy.}

Staff is the important parts to conduct all the work and if the staff is in a low working level, then the working effect will not be very good. So it is necessary to carry out talent's strategy. The enterprise needs a group of processional, highly qualified staff who are very proficient in the grain and cooking oil processing enterprises. These staff can help the enterprises to analyze market quotation and lay down scientific development strategy according to the analysis result. Besides, the staff also can do a good job in the enterprise management to improve its competitiveness. Thus it can be seen that hiring and training a large number of professional talents with full trust can make them apply their abilities to the full. The impact will not be neglected in the future development.

Currently, the development of China's grain and cooking oil processing enterprises has already made some achievement. However, the problem of the shortage of the talents become more and more outstanding and become the bottleneck issue in the enterprise' development. Facing this problem, the enterprises should enhance the training of the staff to make them master much more advanced 
knowledge and apply it into realistic work effectively.In the meantime, the enterprises can employ some well-paid professional personnel and put them in the appropriate positions to adequately excavate their function into the enterprises' development ${ }^{[5]}$. In addition, to improve the comprehensive quality of college students and resolve the talents' shortage problem, the enterprises can run school with some agricultural colleges together.

\section{Enterprise culture cultivating.}

In the long-term development, the enterprises forms its unique spirit and value which consist the corporate culture altogether. Enterprise culture has a significant impact on the development of enterprises, if a company's culture is positive, then the enterprise will be more advantageous in the process of development. Therefore, enterprises must cultivate the enterprise culture to create cultural cohesion and coordination and promote the further development of enterprises. In the process of cultivating the culture, enterprises should adhere to the people-oriented spirit to stimulate the enthusiasm and creativity of staff which promote the staff to put enterprises' development as their working motivation and struggle for the enterprises' future.

\section{Conclusion}

To sum up, grain and cooking oil processing enterprises in our country still have some problems when compared with foreign enterprises. Our country's grain and cooking oil market will be gradually occupied by foreign enterprises if domestic enterprises cannot enhance their competitive power in the process of development, which will further affect our country's economic development. Therefore, enterprises can enhance their competitive power through ways such as technological innovation, management innovation, scientifically identifying development strategy and implementing talent development strategy to occupy certain superiority in the market competition. In the meantime, the government should formulate a series of preferential policies to support the domestic grain and cooking oil processing enterprises so as to create a favorable external environment for their development and to further enhance their competitive power.

\section{References}

[1] Shu Shaobai. Accounting Analysis On Improving The Market Competitiveness Of The Grain And Oil Enterprises. The Modern Economic Information., 2014 (17): 227-228.

[2] Zhao Rumei. The Problems And Countermeasures Of Accounting For Grain And Oil Enterprises. China Economic And Trade, 2015 (14): 178-179.

[3] Yang Zhenhai, Guo Linghao, Kong Caiping, etc., Strengthen The Standardized Management And Innovation Mechanism To Create a Scientific Development Of Grain And Oil Storage Enterprises. China Academy of Sciences, The Seventh National Grain Storage Academic Exchange Conference Papers Set.2010:4-6.

[4] Pingxiang Jiangxi National Grain Reserve: Do a Good Job In The Food Industry To Promote The Industrialization In Food Industry Management. China's Food Economy, 2013 (2): 35-36.

[5] Yang Zhenhai, Guo Linghao, Kong Caiping, etc., To Strengthen The Standardized Management And Innovation Mechanism To Create a Scientific And Technological Development Of Grain And Oil Storage Enterprises. Technological Communications of Grain And Oil Storage Enterprises , 2010,26 (3): 2-4. 